\title{
Genome news highlights loss of chicken strains
}

\author{
Future research is already under threat, as budget cuts wipe out irreplaceable lines.
}

Sir - Publication of the chicken genome sequence and comparative analysis last week (Nature 432, 695-716 and 717-722; 2004), together with a map of more than 2.8 million single nucleotide polymorphisms, is a cause for celebration. The best way to make sense of these data is to manipulate the genes of living organisms. But worldwide stocks of the animals needed to pursue such gene-function studies are dwindling, and in the United States they are being lost to budget cuts. So the future of avian research looks dim despite the opportunities for understanding the genetic bases for development, immunity, host-pathogen interactions and disease resistance offered by the chicken genome project.

Avian stocks are being eliminated in university, government and commercial facilities faced with budget constraints. The crisis described in 2003 by J. E. Fulton and M. E. Delany (Science 300, 1667-1668; 2003) has not been addressed, and additional stocks are being eliminated or threatened. Five different US sites have eliminated stocks in the past year alone. We estimate that at least two-thirds of the developmental mutant lines and more than half the inbred lines held in North America are located in threatened facilities. Unfortunately, given the struggle to maintain living stocks, efforts towards developing new chicken lines for research has virtually stopped. This is in striking contrast to the situation in the mouse, where the generation of new genetic strains has become a priority at almost every major biomedical institution (see "Geneticists prepare for deluge of mutant mice", Nature 432, 541; 2004).

Often the decision to eliminate poultry lines is made with insufficient time to respond. Further, many genetic strains are now held at only one facility, making these vulnerable to loss from disease outbreaks such as avian influenza and exotic Newcastle disease. Today, the only US government support for conservation exists in the National Animal Germplasm Program (NAGP) of the US Department of Agriculture's Agricultural Research Service. This programme, with $\$ 679,000$ funds per year, has a mandate to preserve species from cattle to aquatic organisms, mostly by cryopreservation. The NAGP currently has 162,000 units of animal germplasm; fewer than $1,300(<1 \%)$ are chicken semen samples.
No avian embryo samples or ova are cryopreserved at the NAGP. The nature of avian ova means that current cryopreservation techniques are of limited value.

Both immediate action to preserve the remaining poultry resources and longterm, sustainable solutions are essential. An internationally supported plan needs to be developed and implemented for maintaining avian genetic stocks and exploiting them for both biomedical and agricultural research. Funding is needed to develop facilities - similar to those of the Jackson Laboratory in Bar Harbor, Maine, for mouse strains - to conserve important chicken genetic stocks, to develop means of ova cryopreservation, and to make stocks available for research. Replacing lost stocks, especially of rare inbred strains, will take many years at substantially greater cost than that of preserving what we have now. Marcia M. Miller

City of Hope National Medical Center,

Duarte, California 91010, USA

Signed on behalf of 46 international co-authors, whose names and contact details are available at http://animalscience.ucdavis.edu/AvianResources and http://poultry.mph.msu.edu.

\section{Media affect opinions less than they would like}

Sir - Your Editorial "Going public" (Nature 431, 883; 2004) says "British scientists have seen the public swayed by misleading media coverage of genetically modified (GM) food and vaccines". What evidence do you have for suggesting that there was more media bias one way or the other?

The evidence in the scientific literature suggests that public attitudes to GM foods in a number of European countries were formed independently of the scale and nature of media coverage (see S. Mayer and A. Stirling EMBO Rep. 5, 1021-1024; 2004, and C. Marris, B. Wynne, P. Simmons and S. Weldon Public Perceptions of Biotechnologies in Europe at www.lancs.ac. uk/depts/ieppp/pabe/docs.htm).

This message will be as unwelcome to some on the anti-GM side (who fall into the trap of judging their success by the amount of coverage they get) as to pro-GM scientists and companies, who would rather think that their products were rejected because of unfair media coverage than simply because the public did not want them. Of course, the group to whom this conclusion is least palatable is journalists, who like to think their readers believe every word they write.
However, this ability to make decisions independently of media coverage supports your contention that scientists should trust the public to make a sensible contribution to discussions on research priorities.

Peter Melchett

Soil Association, Bristol House,

40-56 Victoria Street, Bristol BS1 6BY, UK

\section{Brazil's efforts to reverse decline in scholarships}

Sir - I would like to update the details of Brazilian scholarships discussed in Correspondence by A. F. Helene and V. S. Valentinuzzi (Nature 431, 627; 2004).

The downward trend in the number of MSc and PhD scholarships is being reversed by President Luiz da Silva's government, inaugurated in January 2003. The number of PhD and MSc scholarships are: 5,917 and 5,881 (2001); 5,668 and 5,510 (2002); 5,947 and 5,985 (2003); 6,316 and 6,769 (2004).

In addition, in 2004 the National Council for Scientific and Technological Development (CNPq) has allocated an $18 \%$ increase to the scholarships, as an initial effort towards restoring their value.

Moreover, $\mathrm{CNPq}$ has added a monthly 'bench grant' of $30 \%$ on top of the scholarships, to help labs buy specific items needed for students' PhD work.

Erney Plessmann Camargo

CNPq, SEPN 507, Brasilia DF, 70740-901, Brazil

\section{EPA not responsible for 'uninvitation' of a critic}

Sir - Contrary to the claim reported in your News story, "Herbicide critic dropped from pollution conference" (Nature 432, 136; 2004), an official of the US Environmental Protection Agency (EPA) did not "instigate" the "uninvitation" of Dr Tyrone Hayes in the conference sponsored by the Minnesota Pollution Control Agency. The EPA had no involvement in this decision. When Minnesota state officials contacted the EPA about this conference, the EPA only provided them with web links where interested parties could read about the EPA's exhaustive evaluation of atrazine. James J. Jones

Office of Pesticide Programs, US Environmental Protection Agency, 1200 Pennsylvania Avenue NW, Washington DC 20460, USA

The EPA was asked to comment before the News story was printed, but declined to do so - Editor, Correspondence. 